\title{
Tritium-Labeled Compounds IV. D-Glucose-6-t, D-Xylose-5-t, and D-Mannitol-1-t
}

\author{
Horace S. Isbell, Harriet L. Frush, and Joseph D. Moyer
}

(April 13, 1960)

\begin{abstract}
Methods are presented for the preparation of D-glucose- $6-t$, D-xylose- 5 - $t$, and D-mannitol-1- $t$ by the reduction of suitable compounds with lithium borohydride- $t$ in anhydrous tetrahydrofuran, followed by hydrolysis of the products. The starting materials for the reductions are, respectively, 1,2-O-isopropylidene-D-glucurono-6,3-lactone, 5-aldo-1,2-O-isopropylidene$\mathrm{D}$-xylo-pent of uranose, and 2,3:5,6-di- $O$-isopropylidene-D-mannofuranose. The apparatus and procedure for carrying out the reductions in a closed system are described.
\end{abstract}

\section{Introduction and Discussion}

This report is one of a series on the production and use of tritium-labeled carbohydrates. ${ }^{1}$ Previous papers from this laboratory have described convenient apparatus for handling tritium in a closed system $[2],{ }^{2}$ and methods for analyzing nonvolatile tritium 'compounds $[3,4]$. A method for preparing lithium borohydride- $t$ [2], a versatile reductant for introducing tritium into organic compounds, was also given. The usefulness of this compound, in aqueous pyridine, for preparing position-labeled carbohydrates has already been demonstrated [5]; this paper describes its use in the reduction of certain carbohydrate derivatives in an anhydrous solvent.

The equations illustrate the preparation of Dglucose-6- $t$, D-xylose-5-t, and D-mannitol-1- $t$ by reduction of suitable compounds with lithium borohydride- $t$ in anhydrous tetrahydrofuran. Pre-

${ }_{1}$ Project sponsored by the Division of Research of the Atomic Energy Commission. See [1] for a general descriotion of the work.

2 Figures in brackets indicate the literature references at the end of this paper. viously, Sowden had reduced 1,2-O-isopropylideneD-glucurono-6,3-lactone $(\mathrm{I})$ in the preparation of D-glucose- $6-C^{14}[6]$. The reduction, originally carried out with sodium borohydride in water, was improved by Roseman, who used lithium aluminum hydride in anhydrous ether [7]. Crystalline 5-aldo-1,2-Oisopropylidene-D-xylo-pentofuranose (II) [8, 9] was prepared as a starting material for the synthesis of D-glucose-6-C $C^{14}[8]$. Earlier, Sowden had reduced this substance (II), prepared from D-glucose-1-C $C^{14}$, with hydrogen and Raney nickel and obtained D-xylose-1-C $C^{14}$ [10]. Reduction of 5-aldo-1,2-Oisopropylidene-D-xylo-pentofuranose with lithium borohydride- $t$ in tetrahydrofuran, and subsequent hydrolysis, yields D-xylose-5- $t$. The reduction of 2,3:5,6-di- $O$-isopropylidene-D-mannofuranose (III) [11] has been used in this laboratory for several years as a means for analyzing lithium borohydride- $t$. The reduction takes place nearly quantitatively, and the specific activity of the D-mannitol-1-t, readily obtained on hydrolysis, can be used as a measure of the specific activity of the lithium borohydride- $t$.

Synthesis of D-Glucose- $6-t$

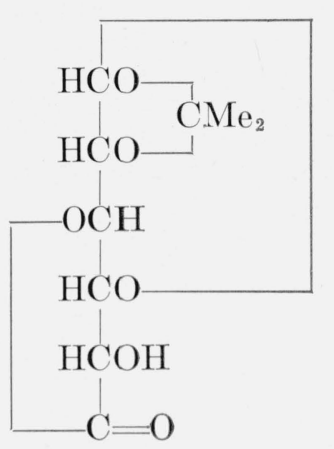

1,2-O-isopropylideneD-glucurono-6,3-lactone

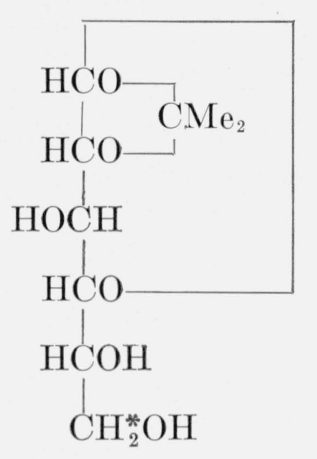

hydrol.

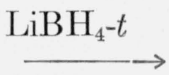

1,2-O-isopropylidene-

D-glucose- 6 - $t$

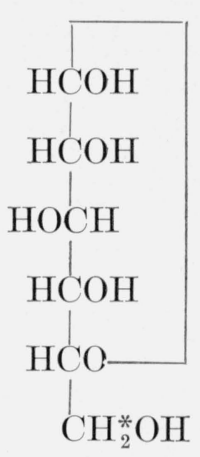

$\alpha$-D-glucose- 6 - $t$ 
Synthesis of D-Xylose- $5-t$

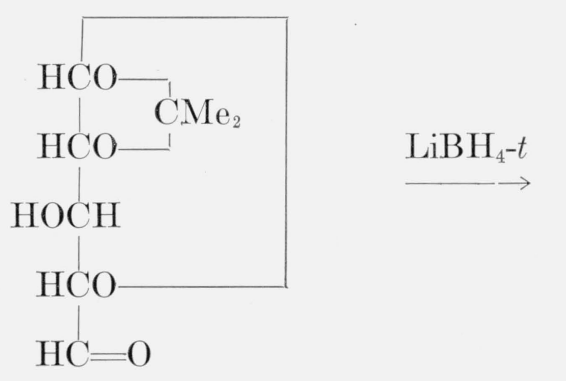

5-aldo-1,2-O-isopropylideneD-xylo-pentofuranose

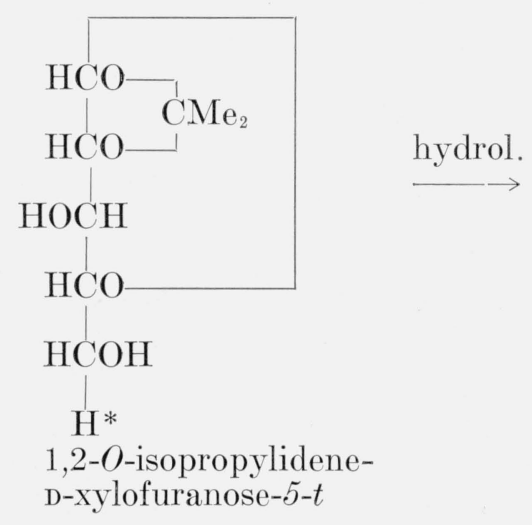

II

Synthesis of D-Mannitol-1-t

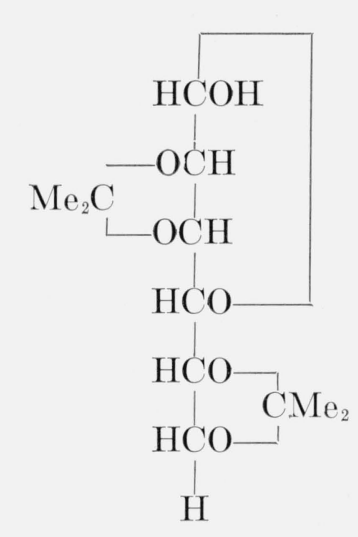

$2,3: 5,6$-di- $O$ -

isopropylidene-

D-mannofuranose

III

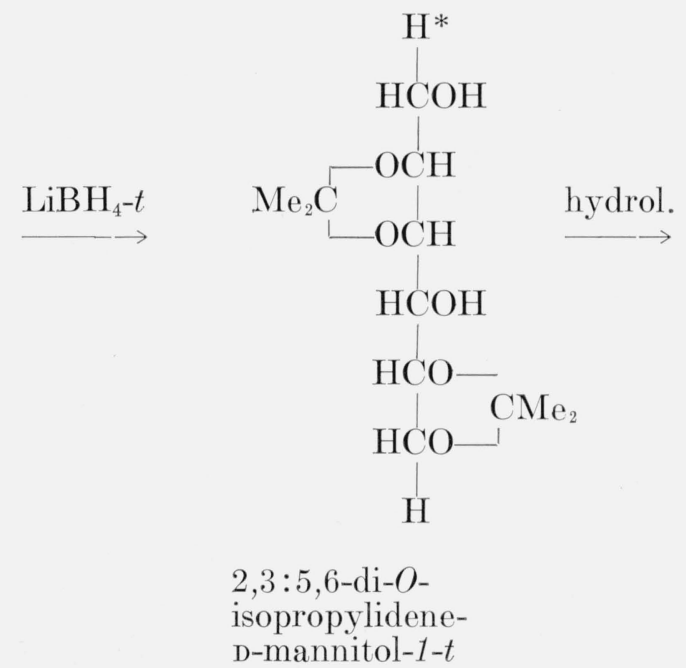

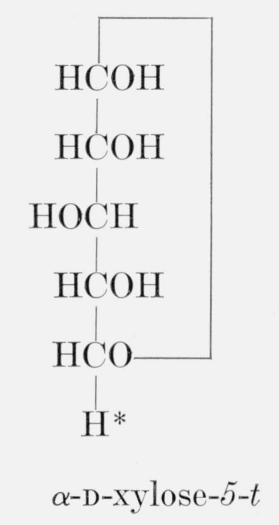




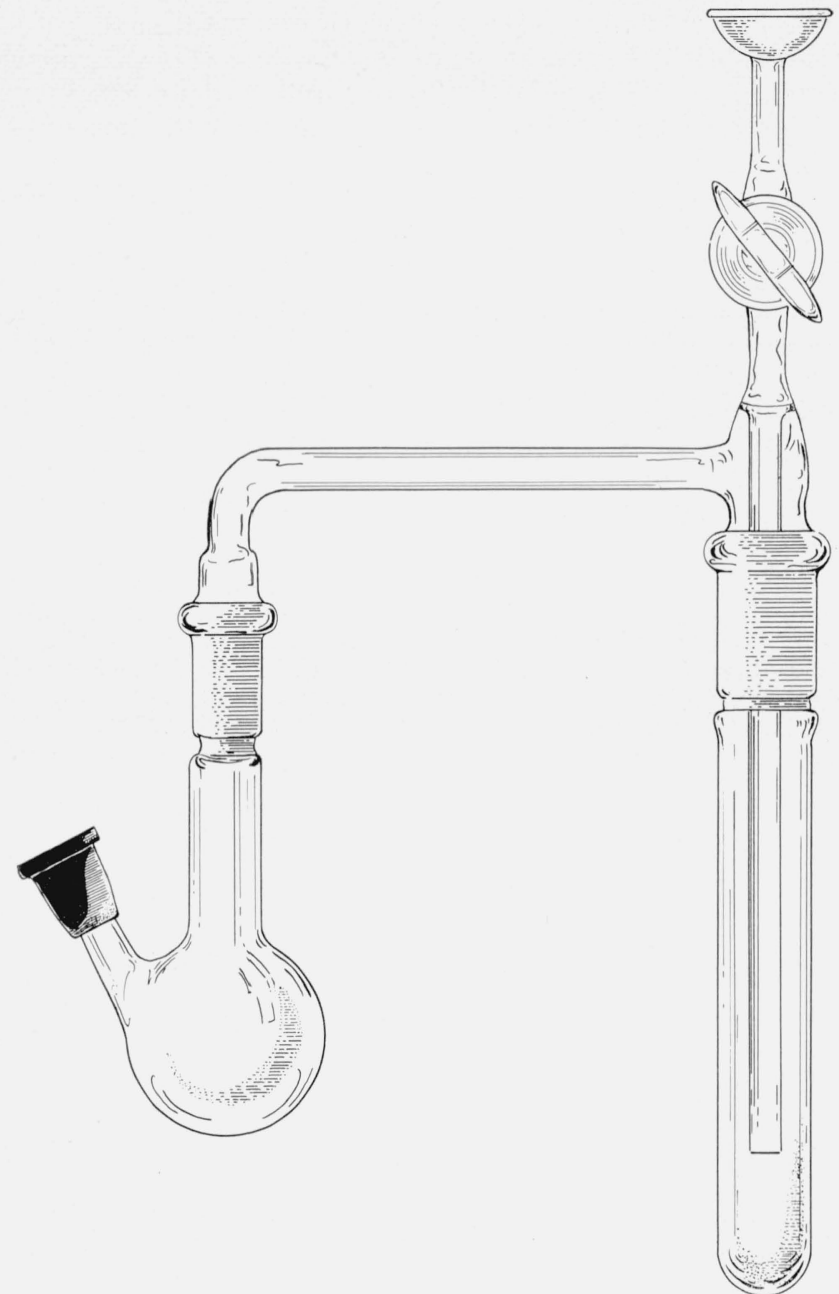

Figure 1. Apparatus for conducting reductions with lithium borohydride-t.

A, A $50-\mathrm{ml}$, round-bottomed reaction flask having a rubber-capped side-arm for introducing reagents.

$B$, Trap for use in cooling-bath

film, $m^{\prime}$ is the weight of the radioactive sample, and $k$ is an empirical factor $\left(4.45 \times 10^{-5}\right)$ independently determined under the conditions employed. Highactivity materials were assayed in formamide solutions, ${ }^{3}$ and the proportional counter was operated at $1,750 \mathrm{v}$. Under the conditions used, 1 count per second corresponds to $0.128 \mu \mathrm{c}$ of tritium per milliliter of the formamide solution counted.

\section{3. $\alpha-\mathrm{D}-$ Glucose- $6-t$}

Two millimoles of 1,2-O-isopropylidene-D-glucurono-6,3-lactone (432 $\mathrm{mg})$ and a magnetic stirring bar were placed in flask A of figure 1. The flask and trap were connected to the general-purpose mani-

3 The method for radioassay in formamide solutions was developed earlier in this laboratory for the assay of carbon-14 [12]. Although the counting-efficiency for tritium is extremely low, the reproducibility of the method is excellent. fold of [2], and the system was made vacuum-tight and evacuated. The connection to the manifold was then closed, and the reaction flask was cooled in a shallow ice-bath set on a magnetic stirrer. The stirrer was started, and $5 \mathrm{ml}$ of anhydrous tetrahydrofuran was injected into the flask by means of a hypodermic needle; this was followed by a solution of 2.0 millimoles of lithium borohydride- $t$ (having a total of $80 \mathrm{mc}$ of radioactivity) in approximately $4 \mathrm{ml}$ of anhydrous tetrahydrofuran. After the solution had remained for $3 \mathrm{hr}$ at $0^{\circ}, 5 \mathrm{ml}$ of water was injected, and the mixture was allowed to stand at room temperature overnight. The reaction mixture was then frozen in liquid nitrogen, and the hydrogen-t that was present was removed through the manifold. The mixture was warmed to room temperature, and $5 \mathrm{ml}$ of water containing 1 millimole of nonradioactive sodium borohydride was added (in order to reduce any aldehyde groups that had escaped reduction with the lithium borohydride- $t$ ). After $30 \mathrm{~min}$, the solution in flask A was frozen, and freeze-dried by cooling B in a dry-ice bath and evacuating the system through the manifold. Water was added to the residue by means of a hypodermic needle, and the solution was again freeze-dried. 'This process was repeated once more.

Finally, flask A was removed from the system, and the residue was dissolved in $20 \mathrm{ml}$ of 1 -percent hydrochloric acid. The solution was heated for $30 \mathrm{~min}$ in a boiling-water bath in order to hydrolyze the isopropylidene group, and was then passed through $20 \mathrm{iml}$ of mixed anion- and cation-exchange resins. ${ }^{4}$ The effluent was concentrated in a rotary still, and all boric acid was removed as methyl borate by repeated addition and evaporation of methanol. The resulting product was dissolved in water, and the solution was passed through a column containing $5 \mathrm{ml}$ of mixed anion- and cation-exchange resins. 'The conductivity of the solution, measured with a purity meter, ${ }^{5}$ was found to be low, in accordance with the absence of ionic impurities. A radioassay of an aliquot of the solution in formamide showed the presence of $33.5 \mathrm{mc}$ of radioactivity in the product. The solution was evaporated almost to dryness in a rotary vacuum still. The residue was dissolved in $1 \mathrm{ml}$ of methanol, and 2-propanol was added almost to the point of incipient turbidity. Crystallization of $\alpha$-D-glucose- 6 - $t$ was induced by seeding with the nonradioactive sugar. The crystals were separated, recrystallized, and assayed in a CMC film by means of the proportional counter. The product weighed $289 \mathrm{mg}^{\circ}$ and had an activity of $29.5 \mathrm{mc}$. By cocrystallization of the mother liquor with nonradioactive D-glucose, about $2 \mathrm{mc}$ of $\alpha$-D-glucose- 6 - $t$ of lower activity was recovered. Thus, the yield of $\mathrm{D}$-glucose- 6 - $t$, based on the 1,2-0-isopropylidene-Dglucurono-6,3-lactone, was 85.7 percent; the radiochemical yield ( $31.5 \mathrm{mc}$ ) was 39.4 percent, based on the lithium borohydride-t.

\footnotetext{
4 A mberlite IR120-H, Rohm \& Haas Co., Philadelphia, Pa., and Duolite A-4 Chemise
}

5 Supplied by Barnstead Still \& Sterilizer Co., Boston, Mass. 


\section{4. $\alpha=$-Xylose-5- $t$}

Four millimoles of crystalline 5-aldo-1,2-O-isopropylidene-D-xylo-pentofuranose were reduced with 2 millimoles of lithium borohydride- $t$ (containing 63.5 me of radioactivity) by the technique described for the preparation of D-glucose- 6 - $t$. A crystalline substance, presumably 1,2-O-isopropylidene-D-xylo-pentofuranose-5-t, separated after the reduction. This intermediate compound was not purified, but was converted to D-xylose-5-t by heating it with 1-percent hydrochloric acid in a boiling-water bath for $1 \mathrm{hr}$. The solution was de-ionized in the manner previously described, and an aliquot was counted in formamide; the solution contained $26.1 \mathrm{mc}$ of radioactivity. The labeled sugar was crystallized by concentrating the solution to a sirup and diluting it with ethanol and 2 -propanol. After recrystallization, the $\alpha$-D-xylose$5-t$ weighed $450 \mathrm{mg}$ and had an activity of $53 \mu \mathrm{c} / \mathrm{mg}$. The yield, based on the weight of the 5-aldo-1,2-Oisopropylidene-D-xylo-pentofuranose, was 75 percent; the radiochemical yield was 38 percent.

\subsection{D-Mannitol-1-t}

One millimole of $2,3: 5,6$-di- $O$-isopropylidene-Dmannofuranose $(260 \mathrm{mg})$ was reduced with 0.5 millimole of lithium borohydride- $t$ containing $16 \mathrm{mc}$ of tritium, by the techniques described in section 2.3.
The crystals that separated were recrystallized from water, with the addition of methanol. The purified D-mannitol-1- $t$ weighed $175 \mathrm{mg}$ and had an activity of $43 \mu \mathrm{c} / \mathrm{mg}$. The chemical yield was 95 percent, and the radiochemical yield, 31.3 percent.

\section{References}

[1] NBS Tech. News Bull. 43, 130 (1959).

[2] H. S. Isbell and J. D. Moyer, J. Research NBS 63A, 177 (1959).

[3] H. S. Isbell, H. L. Frush, and R. A. Peterson, J. Research NBS 63A, 171 (1959).

[4] H. S. Isbell, H. L. Frush, and N. B. Holt, J. Research NBS 64A, 363 (1960).

[5] H. S. Isbell, H. L. Frush, N. B. Holt, and J. D. Moyer, J. Research NBS 64A, 177 (1960).

[6] J. C. Sowden, J. Am. Chem. Soc. \%4, 4377 (1952).

[7] S. Roseman, J. Am. Chem. Soc. 74, 4467 (1952).

[8] R. Schaffer and H. S. Isbell, J. Research NBS 56, 191 (1956) RP2667.

[9] R. Schaffer and H. S. Isbell, J. Am. Chem. Soc. $\mathbf{9 9 ,} 3864$ (1957).

[10] J. C. Sowden, J. Am. Chem. Soc. 73, 5496 (1951).

[11] K. Freudenberg and R. M. Hixon, Ber. deut. chem. Ges. 56, 2119 (1923).

[12] A. Schwebel, H. S. Isbell, and J. D. Moyer, J. Research NBS 53, 221 (1954) RP2537.

Washington, D.C.

(Paper 64A4-60) 